\title{
The rising damp in two traditional clay-brick masonry walls and influence on heat transfer performance
}

\author{
Zhenyi Kong ${ }^{1, *}$, Yonghui $\mathrm{Li}^{1,2}$, Shuichi Hokoi and Shi $\mathrm{Hu}^{1,2}$ \\ ${ }^{1}$ School of Architecture, Southeast University, China \\ ${ }^{2}$ Key Laboratory of Urban and Architectural Heritage Conservation of Ministry of Education \\ (Southeast University), Southeast University, China
}

\begin{abstract}
This paper studies the law of capillary water rise in the brick solid wall and the brick cavity wall under the influence of high-humidity wall foundation. It is found that the rising height of the capillary water sharp front is proportional to the time to the 0.5 power, but the coefficient is related to the wall structure, and the speed in cavity wall is higher than that in the solid wall. The heat flow meter method was used to compare the influence of the capillary water to the heat transfer when it rises to different heights. It is found that the presence of capillary water has a direct impact on the heat transfer coefficient of the wall. The presence of capillary water may increase the heating load by $11.1 \%$ and the cooling load by $15 \%$ of a common historical building in hot summer and cold winter area of China.
\end{abstract}

\section{Introduction}

From the Ming Dynasty to the present, a large number of historical brick buildings have been preserved, such as China's Forbidden City and the ancient city of Pingyao. Many of these buildings are still being used. Most of these historical buildings have only one or two floors. In the rainy season or in the shallow groundwater level area, the wall base of ground floor is easily affected by rainwater, surrounding high-humidity soil, or dynamic underground water. Similar situations also happen in other regions of the world. From 1977 to 1995 , a series of papers were published to provide a systematic introduction to water movement in porous building materials. Christopher Hall and his team applied the modified Darcy equation to unsaturated water flow and developed the sharp front theory and the numerical calculation method [1-3]. In the simplest theoretical model of capillary suction, the capillary penetration depth or height $\mathrm{h}$ is given by the following equation.

$$
h(\mathrm{t})=\sqrt{\frac{r \gamma \cos \theta}{2 \mu}} t^{\frac{1}{2}}=k t^{\frac{1}{2}}
$$

where $r$ is the pore radius of the capillary, $\mathrm{Y}$ is the liquid surface tension, $\theta$ is the wetting angle between liquid and solid phase, $\mu$ is the liquid viscosity, and $t$ is the time. From the view of energy consumption, the clay brick is porous material with a porosity of about $30 \%$

\footnotetext{
* Corresponding author: kongzhenyi@qqq.com
} 
with thermal conductivity of $0.3-0.8 \mathrm{~W} / \mathrm{m} \cdot \mathrm{k}$, while the thermal conductivity of air is 0.0267 $\mathrm{W} / \mathrm{m} \cdot \mathrm{k}$ at a standard atmospheric pressure of $20^{\circ} \mathrm{C}$, and the thermal conductivity of water is $0.59 \mathrm{~W} / \mathrm{m} \cdot \mathrm{k}$, so the increase of the moisture content of the brick will result in an increase in the thermal conductivity. Bednarska's research shows that the rise of moisture content leads up to $125 \%$ increase in thermal conductivity in a red clay brick experiment [4], Salmon [5] considers that the increasing water content in the brick will lead to the change of heat transfer coefficient of the brick wall, and heating energy consumption to rise in winter.

\section{Methods}

\subsection{Experimental facilities and materials.}

This study used traditional masonry techniques and Chinese bonding materials (a simple mixture of lime and sand) to build the experimental walls. In the test chamber, blue bricks and traditional mortar were used to construct two different traditional walls, a solid brick wall and a cavity wall, which divided the chamber into room 1 and room 2 as shown in Fig.1, Fig.2 and Fig.6. The size of a single brick was $240 \mathrm{~mm} * 112 \mathrm{~mm} * 48 \mathrm{~mm}$. The average bulk density of the brick was $1.49 \mathrm{~g} / \mathrm{cm} 3$, the water absorption rate after soaking for $24 \mathrm{~h}$ was $15.0 \%$, the water content after boiling for $5 \mathrm{~h}$ was $16.5 \%$, and the water saturation coefficient was $90.9 \%$. Water tanks of $0.5 \mathrm{~m}$ depth were installed at the bottom. RTR-53A units were used to record temperature and relative humidity in two rooms. A Testo 616 water content meter with special calibration was used to measure the mass water content at different height and the sharp front height (which could reflect the overall water content in $5 \mathrm{~cm}$ depth) [6].

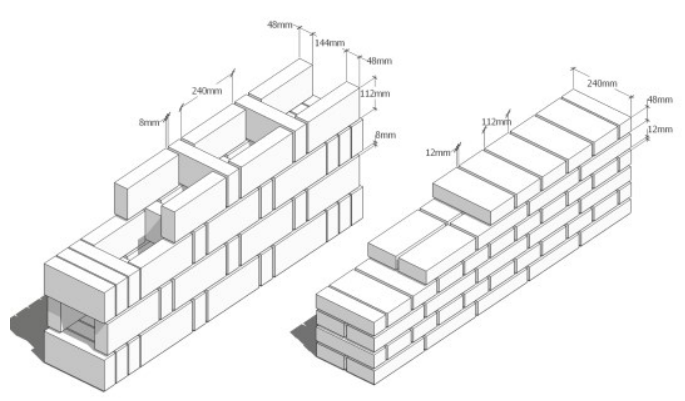

Fig. 1. Solid and cavity wall.

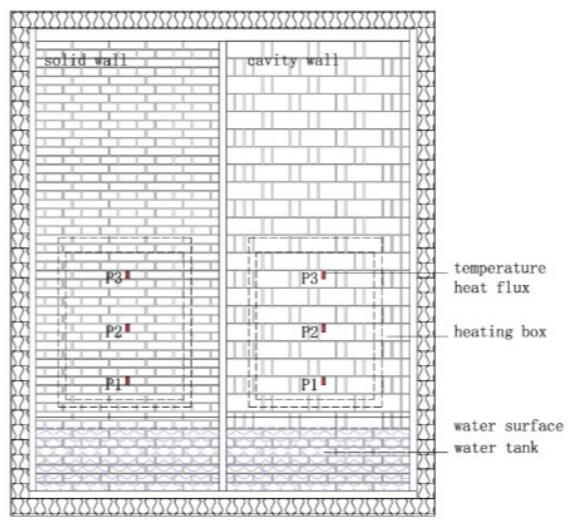

Fig. 2. Front elevation of the two walls.

Three pairs of heat flow meters (HS-30, Captec) were installed at a height of $70 \mathrm{~cm}(\mathrm{P} 1)$, $110 \mathrm{~cm}(\mathrm{P} 2)$, and $140 \mathrm{~cm}(\mathrm{P} 3)$ in both side of the wall, which measure the difference of the surface temperature and the heat flow cross the walls. The height of the hot box coverage ranged from $60 \mathrm{~cm}$ to $150 \mathrm{~cm}$, and the coverage width was $80 \mathrm{~cm}$.

IN-T and OUT-T represent the surface temperature on both sides of the point. In-q and Out-q represent the heat fluxes on both sides, $\mathrm{q}$ is average value of them. $\mathrm{R}$ is the thermal resistance at this point, $\mathrm{K}$ is the heat transfer coefficient of the wall, and the internal surface heat transfer resistance $\mathrm{Ri}$ is $0.11\left(\mathrm{~m}^{2} \cdot \mathrm{K}\right) / \mathrm{W}$ when the heat transfer coefficient is calculated. The external surface heat exchange resistance $\operatorname{Re}$ is $0.04\left(\mathrm{~m}^{2} \cdot \mathrm{K}\right) / \mathrm{W}$.

$$
\mathrm{R}=\frac{\mathrm{T} 1-\mathrm{T} 2}{q}
$$




$$
\mathrm{K}=\frac{1}{R e+R+R i}
$$

Then we get the $\mathrm{K}$ value of the wall which reflect the thermal conductivity of the wall.

\subsection{Procedure}

At first both of the walls were dry, the average water content is about $0.5 \%$. We measured the heat transfer coefficient at three different heights of the both walls. Then we put water into the tanks and continually measured the height of the sharp front height of capillary water for 6000 hours. During this period, we measured the heat transfer coefficient of the both walls for two times. More information in table 1.

Table 1. Heat transfer experiment conditions and time table.

\begin{tabular}{|c|c|c|c|c|c|c|}
\hline Date & $\begin{array}{c}\text { Time } \\
\text { ( hours } \\
\text { from adding } \\
\text { water })\end{array}$ & Object & $\begin{array}{c}\text { Capillary water } \\
\text { height }(\mathrm{m})\end{array}$ & $\begin{array}{c}\text { Heating } \\
\text { temperat } \\
\text { ure }\left({ }^{\circ} \mathrm{C}\right)\end{array}$ & $\begin{array}{c}\text { RH/TEM } \\
\text { in room1 }\end{array}$ & $\begin{array}{c}\text { RH/TEM } \\
\text { in room2 }\end{array}$ \\
\hline $1 / 28$ & 0 & cavity wall & 0 & 35 & $11 / 45 \%$ & $15 / 33 \%$ \\
\hline $2 / 6$ & 0 & solid wall & 0 & 35 & $13 / 42 \%$ & $17 / 30 \%$ \\
\hline $4 / 22$ & 650 & solid wall & 0.85 & 35 & $23 / 88 \%$ & $25 / 84 \%$ \\
\hline $5 / 16$ & 1200 & cavity wall & 1.15 & 40 & $24 / 88 \%$ & $26 / 85 \%$ \\
\hline $10 / 11$ & 4700 & cavity wall & 1.8 & 40 & $24 / 86 \%$ & $25 / 86 \%$ \\
\hline $11 / 19$ & 5600 & solid wall & 1.6 & 40 & $23 / 87 \%$ & $24 / 86 \%$ \\
\hline
\end{tabular}

\section{Results}

\subsection{Results of sharp front rising.}

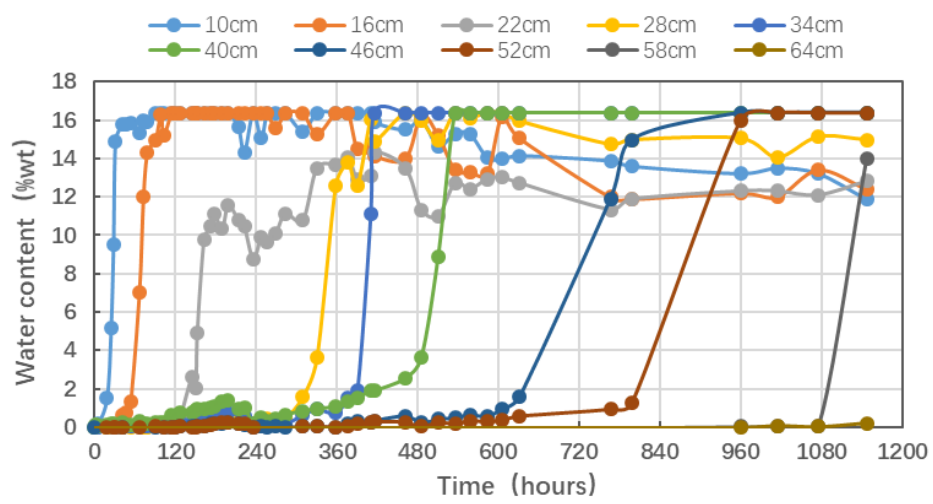

Fig. 3. Moisture content at different heights in the solid wall.

Fig. 3 shows the change in the measured water content at different heights from water surface over 1150 hours in the solid wall. When the sharp front of the capillary water reached a certain height, the moisture content at that height increased to and stayed around saturation. The sharp front reached the height of $16 \mathrm{~cm}, 34 \mathrm{~cm}$ and $46 \mathrm{~cm}$ at approximately hour 100, hour 410 and hour 760, respectively. Until about hour 200, the sharp front rose quickly. It then rose slowly as time progressed. 


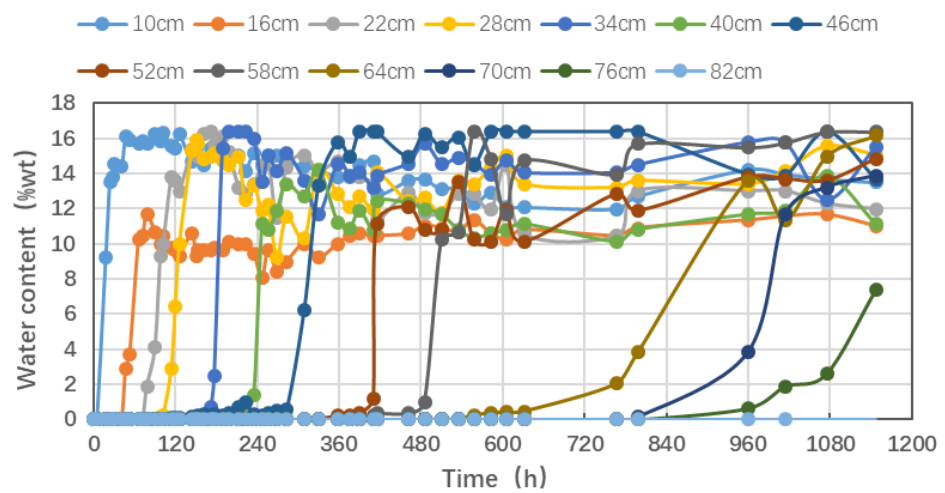

Fig. 4. Moisture content at different heights in the cavity wall.

Fig. 4 shows the change in the water content at different heights in the cavity wall. In general, the capillary action trend in the cavity wall is similar to that in the solid wall. The capillary water reached the height of $16 \mathrm{~cm}, 34 \mathrm{~cm}$ and $46 \mathrm{~cm}$ at approximately hour 72 , hour 190 and hour 310, respectively. The rising speed in the cavity wall was obviously higher than that in the solid wall.

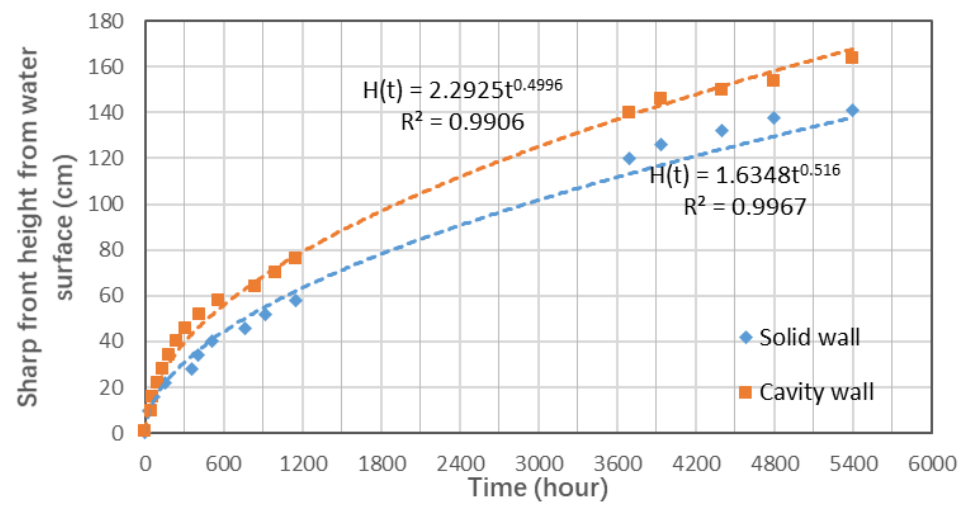

Fig. 5. The relationship between the height of sharp front raise and time.

The measurement of the sharp front was explained in other paper [6]; the points in Fig. 5 show sharp front height with time. It is clear that in the solid wall, the relationship between sharp front height and time is consistent with the law $h(t)=k t^{\frac{1}{2}}$ from past research. Although the cavity wall is different from the solid wall regarding masonry method, the rising of the sharp front in the cavity wall is also expressed by the law $h(t)=$ $k t^{\frac{1}{2}}$ (Fig.5). The curves show a fitting relationship, and the fitting equations and variance are also given. The different values of parameter $\mathrm{k}$ reflect the masonry method's influence on the rule of rising damp.

The solid wall: $\mathrm{H}(\mathrm{t})=2.2925 \mathrm{t}^{0.4996}\left(\mathrm{R}^{2}=0.9906\right)$

The cavity wall: $\mathrm{H}(\mathrm{t})=1.6348 \mathrm{t}^{0.516}\left(\mathrm{R}^{2}=0.9967\right)$

where $\mathrm{t}$ is the time (hour), and $\mathrm{H}(\mathrm{t})$ is the sharp front height at the time $\mathrm{t}$. 


\subsection{Results of heat transfer coefficient change.}
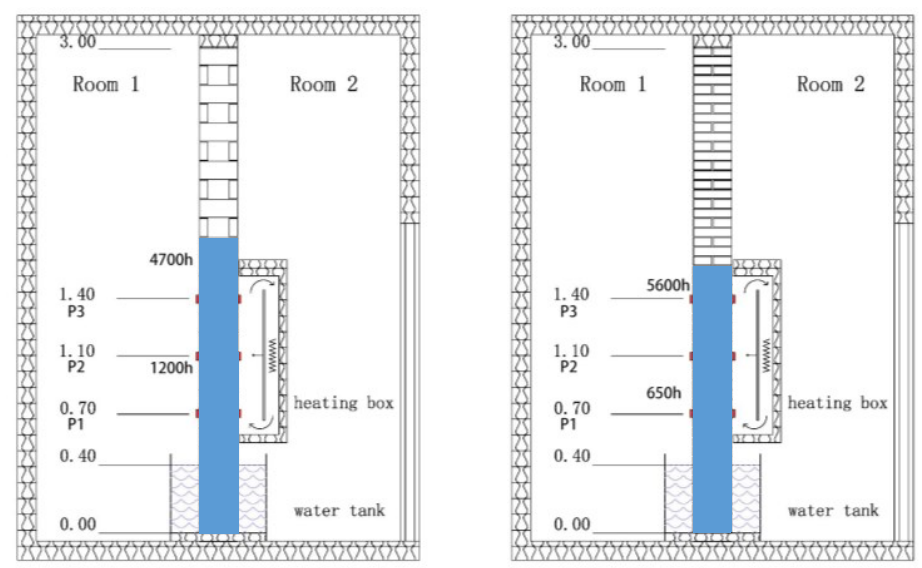

Fig. 6. Section of the two walls and the devices.

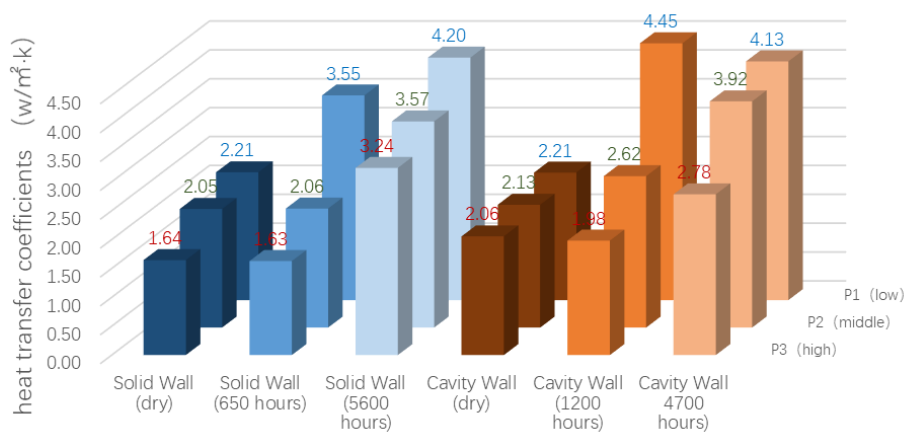

Fig. 7. $\mathrm{K}$ value at different points of the walls at different period.

As shown in fig.7, in dry condition, except P3 in solid wall (maybe there is an air crack in the wall), the $\mathrm{K}$ value at other 5 points in solid wall and cavity wall are similar, from 2.05 to $2.21 \mathrm{~W} / \mathrm{m}^{2} \cdot \mathrm{k}$.

In solid wall, after hour 650 , when sharp front rose $15 \mathrm{~cm}$ above $\mathrm{P} 1$, the $\mathrm{K}$ value of this point increased to $3.55 \mathrm{~W} / \mathrm{m}^{2} \cdot \mathrm{k}$, while the $\mathrm{K}$ value of upper two points remain unchanged. After hour 5600 , the sharp front rose to $15 \mathrm{~cm}$ above P3, all the three points got obviously increase.

In cavity wall, after hour 1200 , when sharp front just reaches $\mathrm{P} 2$, the $\mathrm{K}$ value of $\mathrm{P} 1$ increased to $4.45 \mathrm{~W} / \mathrm{m}^{2} \cdot \mathrm{k}$, the $\mathrm{K}$ value of $\mathrm{P} 2$ increased to $2.62 \mathrm{~W} / \mathrm{m}^{2} \cdot \mathrm{k}$, the $\mathrm{K}$ value of $\mathrm{P} 3$ decreased $0.08 \mathrm{~W} / \mathrm{m}^{2} \cdot \mathrm{k}$. After hour 4700 , the sharp front rose to $30 \mathrm{~cm}$ above $\mathrm{P} 3$, the $\mathrm{K}$ value of P2 and P3 got obviously increase. But the K value of P1 decreased by $7 \%$, this may be caused by the decrease of water content at P1 during that period. In general, the $\mathrm{K}$ value of the lower point is higher than that of upper one, the same situation in water content at different height of the solid wall. 


\section{Discussion}

Though the sharp front in both walls rose continuously by the law $h(t)=k t^{\frac{1}{2}}$, the rising speed in the two walls was clearly different. In the cavity wall, it took 310 hours for the capillary water to reach a height of $46 \mathrm{~cm}$; however, in the solid wall, it took 760 hours. The rising speed in the cavity wall was higher than that in the solid wall. In general, the reason is that the horizontal section area of the cavity wall is less than that of the solid wall, and the thickness of the mortar is also less than that of the solid wall. Though the sharp front is influenced by climate

For thermal performance, the heat transfer coefficient is obviously influenced by water content, which would increase the heating and cooling load. If we apply the experiment result to a common Chinese traditional single floor house of $45 \mathrm{~m}^{2}$ located in Nanjing, the rising damp in walls will increase the cooling load by $15.3 \%$ and heating load by $11.1 \%$. So it is very important to control the rising damp in wall, by which also improve the indoor environment and construction durability.

For the next step, we will compare the experimental results (water rise and heat transfer) with numerical simulation to verify the calculation model. After that, we can apply the model into energy saving and brick heritage conservation.

This work was supported by NSFC (grant no. 51878140) and Natural Science Foundation of Jiangsu Province (no. BK20161424). Funding partially also comes from Zhong Ying Young Scholar of Southeast University, and Jiangsu Provincial Cultural Research Project (no. 2017SK01 and no. 2018SK01).

\section{References}

1. R.J. Gummerson, C. Hall, W.D. Hoff, Build. Environ. 15, 101-108(1980)

2. C. Hall, Build. Environ. 16, 201-207 (1981)

3. C. Hall, W.D. Hoff, Proc. R. Soc. A Math. Phys. Eng. Sci. 463, 1871-1884 (2007)

4. D. Bednarska, M. Koniorczyk, AIP Conf. Proc. 1866 (2017)

5. D.R. Salmon, R.G. Williams, R.P. Tye, ASTM Spec. Tech. Publ., 1426, 58-78(2002)

6. Y.H. Li, Z.Y. Kong, S. Hokoi, Y. Ma, J.G. Wang, Build. Environ. (in publication) 